\title{
EDITORIAL
}

\section{LONELINESS AND SOCIAL ISOLATION IN OLDER ADULTS DURING THE COVID-19 PANDEMIC: IMPLICATIONS FOR GERONTOLOGICAL SOCIAL WORK}

\author{
M. BERG-WEGER ${ }^{1,2}$, J.E. MORLEY ${ }^{2}$ \\ 1. School of Social Work, Saint Louis University, St. Louis, Missouri, USA; 2. Division of Geriatric Medicine, Saint Louis University School of Medicine, St. Louis, Missouri, USA.

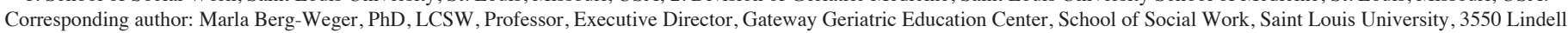 \\ Boulevard, St. Louis, MO 63103, USA, Email: marla.bergweger@slu.edu
}

Key words: Loneliness, COVID-19 pandemic, social isolation, quality of life, depression.

Social workers and other gerontological scholars have increasingly voiced concern about loneliness (subjective perception of lack of meaningful relationships) and social isolation (social engagements and contacts) among older adults. In 2015, "Eradicate Social Isolation" was included as one of the twelve Grand Challenges for Social Work (1). As key members of interprofessional geriatric teams, social workers are uniquely positioned to intervene in addressing social isolation by developing and testing interventions1. By 2017, calling it a "loneliness epidemic", U.S. Surgeon General Vivek Murthy proclaimed loneliness and social isolation among the world's older adult population was a global epidemic (2).

As prevalence rates suggest that nearly one-third of older adults experience loneliness and/or social isolation and a subset (5\%) reporting often or always feeling lonely $(3,4)$, we began to recognize the risks and impacts. Data on impact of loneliness and social isolation indicates significant and long-term negative outcomes for older adults identified as lonely and/or socially isolated. As noted in an earlier editorial (5), there are myriad negative physical and mental health outcomes that are linked to the older adult experiencing loneliness and/or social isolation. While issues of loneliness and social isolation can often be overlooked by health and social service professionals, the COVID-19 pandemic has focused increased attention on social isolation and loneliness for all ages, particularly older adults as the most vulnerable, at-risk segment of the population.

Social workers working in healthcare organizations, residential communities, and social service agencies have been on the front lines of ensuring the safety and engagement of older adults during the crisis. Knowing the factors that place older adults at risk for loneliness and social isolation became critical for assessing older adults, including living alone or in a rural community, poor functional status, widowhood, being female, lower income/education, losses, depression, and feeling misunderstood by others (6-11). With sheltering-in-place and stay-at-home orders, many older adults lost usual ways to connect with support networks and health and social service providers and are spending increased time alone. Many of the traditional strategies for engaging older adults have become obsolete in the new normal. Congregate meal sites, exercise and social activities, in-person health/business interactions, and volunteer and employment commitments are among those engagement opportunities that are suspended.

Social workers serving the populations that are the most vulnerable to COVID-19, have become creative and resourceful in staying connected to our older adult clients, patients, friends, and families and supporting their efforts to stay connected with others to allay loneliness, social isolation, and anxiety. In-person activities and contacts began to be facilitated virtually through individual devices and videoconferencing. Social distancing, personal protective equipment and virtual reality devices were introduced. Daily telephone reassurance calls, home delivery services, virtual and phone health care visits, and prevention education and news updates became a part of social work practice. Social work practice with older adults changed dramatically and quickly.

What are we learning from this experience? As two Italian geriatricians noted in April, 2020, we have a "unique opportunity for improvement" (12). While the world will hopefully gain new knowledge and awareness regarding preparedness and response from the 2020 pandemic, gerontological social workers can take this time to assess the ways in which they built on their knowledge, skills, and values to respond to the crisis. Social workers and other health professionals are learning from this crisis:

- Assessing loneliness and social isolation-Because providers seldom ask about these experiences, having tools that can be easily and quickly administered to determine if the older adult is lonely or socially isolated is critical. Training for practitioners in assessing these issues is minimal at best (13). There are several available tools; we have developed a rapid tool, the ALONE scale (table 1) whose psychometric validation is underway. Assessing the risk factors previously noted should be included as part of the ongoing assessment of older adults' needs.

- Developing and adapting evidence-based interventions to address loneliness and social isolation-Lubben and colleagues (1) note that social workers should collaborate 
Table 1

ALONE Scale

\begin{tabular}{|c|c|c|c|c|}
\hline A & Are you Attractive (as a friend) to others? & Yes___ & Sometimes___ & No__ \\
\hline $\mathrm{L}$ & Are you Lonely? & Yes___ & Sometimes___ & No_ \\
\hline $\mathrm{O}$ & Are you Outgoing/friendly? & Yes___ & Sometimes___ & No_ \\
\hline $\mathrm{N}$ & Do you feel you have No friends? & Yes___ & Sometimes___ & No__ \\
\hline $\mathrm{E}$ & Are you Emotionally upset (sad)? & Yes___ & Sometimes___ & $\mathrm{No}$ \\
\hline
\end{tabular}

with others to develop and test interventions - the pandemic crisis provides the opportunity to respond to the charge. Social workers can go beyond traditional support group approaches to create compassionate social communities that employ new, innovative methods (e.g., virtual/ telehealth delivery formats) and intervention components (e.g., laughter, mindfulness, meditation, reminiscence, and horticulture therapy, body movement (e.g., exercise, dancing, yoga).

Our interprofessional Geriatric Workforce Enhancement Program (GWEP) team has adapted one such evidence-based group intervention. Circle of Friends $(\mathrm{C}$ is a group intervention developed at Helsinki University designed to address loneliness and social isolation via weekly sessions over three months that incorporate art and inspiring activities, exercise/health content, and therapeutic writing (14-16). Outcomes indicate decreased loneliness, social isolation, and healthcare costs and increased feelings of well-being (17-18). In response to COVID-19, our partners are offering education-focused video conferences and doing daily phone check-in calls.

Social workers in residential facilities have faced a variety of challenges. With families not being able to visit, they have been forced to develop innovative ways for family visits from window visits to Face Time. Developing meaningful activities that can be facilitated in the residents' rooms or re-thinking how to offer group activities such as "Biongocise" (bingo with exercise) with appropriate social distancing. Social workers have organized compassionate visits for persons at the end-oflife. Providing daily updates on residents to family members has been a mainstay of social workers' routines. These include a variety of digital approaches such as face time, whatsapp, skype, and zoom. Writing letters to God about their life has also been an innovative way to communicate with relatives.

In the post-pandemic world, we can use these crisis intervention strategies to evolve our preparedness skills moving forward. Encouraging our patients and clients to engage in advanced care planning is one area for improvement (only $70 \%$ of older adults assessed in our Geriatric Workforce Enhancement Program have completed an advanced directive).

- Learning new skills-technology, importance of preparedness, and how to engage with people in non- traditional ways can become a part of social work practice. Having had to quickly respond during the pandemic necessitated the use of technology that was previously unfamiliar for both professionals and older adults and planning in a time of little, often conflicting information and rapidly evolving status. Once the crisis has passed, we can evaluate our responses and identify those strategies that worked and can become a part of our practice approaches. For example, we moved forward to develop a telehealth delivery platform to facilitate Circle of Friends for use during the crisis and beyond. With social workers embracing the use of technology as a viable service-delivery option, traditional interventions can similarly be offered (e.g., exercise, dementia care, and caregiver support) as well as more innovative options (e.g., interactive photo sharing, support and learning assistants, online-based websites for pairing runners and cooks with isolated older adults, and multi-party games) (19). In addition, there will be a need to learn to identify Post Traumatic Stress Disorder. Symptoms such as fear, sleeping disturbances, poor concentration and flash backs. In the future, we may see more social worker interactions carried out through digital connections along with increasing use of "Alexa" and a variety of health robots to help alleviate loneliness.

- Continuing to combat ageism-now that the majority of our society has experienced loneliness and social isolation, there is better understanding of the need to not perpetuate it in a post-pandemic world, particularly with older adults. COVID19 has triggered more public ageism (i.e., people display relief when they initially learned the majority of those dying from the virus are older adults) (12).

While the COVID-19 pandemic has forced the world to change the way in which we live, let us as scholars view it as an opportunity to assess our responses, identify lessons learned, and develop strategies and approaches to address loneliness and social isolation among older adults. While we will continue to provide the same services, we may find that, along with our interprofessional colleagues, we can all envision expanded perspectives on our roles. Lastly, we must consider the needs that will arise in the post-pandemic era for our patients and their families who may experience increased depression, anxiety, and 


\section{LONELINESS AND SOCIAL ISOLATION IN OLDER ADULTS DURING THE COVID-19 PANDEMIC}

financial challenges. As we have helped them to transition into the world created by the COVID-19 crisis, we can be there to help them transition into the post-COVID-19 world. We must be cognizant of the fact that each person experiences loneliness and social isolation in their own unique way and our responses must be tailored to meet those individual needs that is grounded in evidence-based practice (20-21).

Conflict of interest: The authors declare there are no conflicts.

Funding: This project is supported by the Health Resources and Services Administration (HRSA) of the U.S. Department of Health and Human Services (HHS) under grant number U1QHP28716, Geriatrics Workforce Enhancement Program, for $\$ 750,000$. This information or content and conclusions are those of the author and should not be construed as the official position or policy of, nor should any endorsements be inferred by HRSA, HHS, or the U.S. Government.

\section{References}

1. Lubben J, Gironda M, Sabbath E, Kong J, Johnson C. Social isolation presents Grand Challenge for social work. Working Paper No. 7, American Academy of Social Work and Social Welfare Grand Challenges for Social Work Initiative. 2015. Retrieved from https://aaswsw.org/wp-content/uploads/2015/03/Social-Isolation-3.24.15.pdf

2. Murthy V. Work and the loneliness epidemic. Harvard Business Review, September 2017. Retrieved from: https://www.vivekmurthy.com/single-post/2017/10/10/Workand-the-Loneliness-Epidemic-Harvard-Business-Review .

3. Jansson AH, Savikko NM, Pitkala KH. Training professionals to implement a group model for alleviating loneliness among older people-10-year follow-up study. Educational Gerontology 2017. DOI: 10.1080/03601277.2017.1420005.

4. Savikko M, Routasalo P, Tilvis RS, Strandberg TE, Pitkala KH. Predictors and subjective causes of loneliness in an aged population. Archives of Gerontology and Geriatrics. 2005;41:223-233.

5. Berg-Weger M, Morley JE. Loneliness in older age: An unaddressed health problem. J Nutr Health Aging. 2020; 24(3): 243-245.

6. Jakobsson U, Hallberg IR. Loneliness, fear, and quality of life among elderly in Sweden: A gender perspective. Aging Clinical and Experimental Research 2005; $17: 494-501$
7. AARP. A national survey of adults 45 and older. Loneliness and social connections. AARP Foundation 2012. Doi.org/10/26419/res.00246.001

8. Cohen-Mansfield J, Perach R. Interventions for alleviating loneliness among older persons: A critical review. Am J Hlth Prom 2015;29:e109-e125.

9. Lee E, Depp C, Palmer BW, et al. High prevalence and adverse health effects of loneliness in community-dwelling adults across the lifespan: Role of wisdom as a protective factor. Intl Psychogeriatrics 2019;31:10:1447-1462.

10. Routasalo PE, Savikko N, Tilvis RS, Strandberg TE. Social contacts and their relationship to loneliness among aged people-a population-based study. Gerontology 2006;52:181-187.

11. Savikko N, Routasalo P, Tilvis RS, Strandberg T, Pitkala KH. Predictors and subjective causes of loneliness in an aged population. Arch Geron Geriatr 2005;41:223-233.

12. Cesar M, Proietti M. Geriatric medicine in Italy in the time of COVID-19. J Nutr Hlth Aging, 2020: 24: 1-2

13. Pitkala KH, Routasalo P, Kautiainen H, Tilvis RS. Effects of psychosocial group rehabilitation on health, use of health care services, and mortality of older person suffering from loneliness: A randomized, controlled trial. J Geron 2009;64A:792-800.

14. Anu J, Tarja Y, Satu H, Pitkala K. Circle of Friends. Group model alleviating loneliness. Retrieved from https://vtkl.fi/toiminta/ystavapiiri

15. Pitkala KH et al. Leading groups of older people: A description and evaluation of the education of professionals. Edl Geron 2004;30:821-833.

16. Routasalo PE, Arve, Lauri S. Geriatric rehabilitation nursing: Developing a model Intl J Nurs Prac 2004;10:207-215.

17. Routasalo PE, Tilvis RS, Kautiainen H, Pitkala KH. Effects of psychosocial group rehabilitation on social functioning, loneliness and well-being of lonely, older people: Randomized controlled trial J Adv Nurs 2008;65:297-305

18. Savikko N, Routasalo P, Tilvis S, Pitkala KH. Psychosocial group rehabilitation for lonely older people: A description of intervention and participants' feedback. Int $\mathbf{J}$ Older People Nurs 2010;5:16-24.

19. Griffiths H. Social isolation and loneliness in the UK with a focus on the use of technology to tackle these conditions. 2017. Available from: https://iotuk. org.uk/ wp-content/uploads/2017/04/Social-Isolation-and-Loneliness-Landscape-UK.pdf.

20. Fakoya OA, McCorry NK, Donnelly M. Loneliness and social isolation interventions for older adults: a scoping review of reviews. BMC Publ Health, 2020; 20:129 https:// doi.org/10.1186/s12889-020-8251-6

21. Landeiro F, Barrows P, Nuttall Musson E, Gray A, Leal J. Reducing social isolation and loneliness in older people: a systematic review protocol. BMJ Open 2016;7(5):e013778 Available from: http://www.pubmedcentral.nih. gov/articlerender. fcgi?artid=PMC5623425 